\title{
BRAF and TERT mutations in papillary thyroid cancer patients of Latino ancestry
}

\author{
Ana P Estrada-Flórez $1,2,3$, Mabel E Bohórquez ${ }^{2}$, Alejandro Vélez ${ }^{4,5}$, Carlos S Duque ${ }^{5}$, Jorge H Donado ${ }^{5}$, Gilbert Mateus ${ }^{6}$, \\ Cesar Panqueba-Tarazona ${ }^{7}$, Guadalupe Polanco-Echeverry ${ }^{1}$, Ruta Sahasrabudhe ${ }^{1}$, Magdalena Echeverry ${ }^{2}$ and \\ Luis G Carvajal-Carmona ${ }^{1,4,8,9}$ \\ ${ }^{1}$ Genome Center and Department of Biochemistry and Molecular Medicine, School of Medicine, University of California, Davis, California, USA \\ ${ }^{2}$ Grupo de Citogenética, Filogenia y Evolución de Poblaciones, Facultad de Ciencias y Facultad de Ciencias de la Salud, Universidad del Tolima, Ibagué, \\ Tolima, Colombia \\ ${ }^{3}$ Facultad de Ciencias para la Salud, Universidad de Caldas, Manizales, Caldas, Colombia \\ ${ }^{4}$ Dinamica IPS, Medellín, Antioquia, Colombia \\ ${ }^{5}$ Hospital Pablo Tobón Uribe, Medellín, Antioquia, Colombia \\ ${ }^{6}$ Hospital Federico Lleras Acosta, Ibagué, Tolima, Colombia \\ ${ }^{7}$ Universidad Surcolombiana, Neiva, Huila, Colombia \\ ${ }^{8}$ University of California Davis Comprehensive Cancer Center, Sacramento, California, USA \\ ${ }^{9}$ Fundación de Genética y Genómica, Medellín, Antioquia, Colombia
}

Correspondence should be addressed to L G Carvajal-Carmona: Igcarvajal@ucdavis.edu

\begin{abstract}
Papillary thyroid cancer (PTC) is the second most commonly diagnosed malignancy in U.S. Latinas and in Colombian women. Studies in non-Latinos indicate that BRAF and TERT mutations are PTC prognostic markers. This study aimed to determine the prevalence and clinical associations of BRAF and TERT mutations in PTC Latino patients from Colombia. We analyzed mutations of BRAF (V600E) and TERT promoter (C228T, C250T) in tumor DNA from 141 patients (75 with classical variant PTC, CVPTC; 66 with follicular variant PTC, FVPTC) recruited through a multi-center study. Associations between mutations and clinical variables were evaluated with Fisher exact tests. Survival was evaluated with Kaplan-Meier plots. Double-mutant tumors (BRAF+/TERT+, $n=14$ patients) were more common in CVPTC $(P=0.02)$. Relative to patients without mutations $(n=48)$, double mutations were more common in patients with large tumors $(P=0.03)$, lymph node metastasis $(P=0.01)$, extrathyroid extension $(P=0.03)$, and advanced stage $\left(P=6.0 \times 10^{-5}\right)$. In older patients, TERT mutations were more frequent (mean age 51 years vs 45 years for wild type TERT, $P=0.04$ ) and survival was lower $(\mathrm{HR}=1.20 ; P=0.017)$; however, given the small sample size, the decrease in survival was not statically significant between genotypes. Comparisons with published data in US whites revealed that Colombian patients had a higher prevalence of severe pathological features and of double-mutant tumors (10 vs $6 \%, P=0.001$ ). Mutations in both oncogenes show prognostic associations in Latinos from Colombia. Our study is important to advance Latino PTC precision medicine and replicates previous prognostic associations between BRAF and TERT in this population.
\end{abstract}

\section{Key Words}

- cancer risk factors

- somatic mutations

- Hispanics

- BRAF

- TERT

\section{Introduction}

In the United States and several other countries, the incidence of papillary thyroid cancer (PTC) has significantly increased in recent decades (1). PTC is now the second most commonly diagnosed malignancy among US Latinas $(2,3)$. In Colombia, the country with the second largest Latino population in Latin America $(4,5)$, https://ec.bioscientifica.com

https://doi.org/10.1530/EC-19-0376 (c) 2019 The authors Published by Bioscientifica Ltd

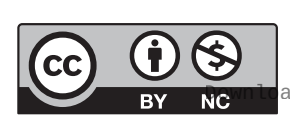

This work is licensed under a Creative Commons Attribution-NonCommercial 4.0 International License. ded from Bioscientifica.com at 04/26/2023 08:25:12AM 
incidence has also been increasing and PTC is now the third most common female cancer with an age-standardized rate of 14.5 per 100,000 people $(4,5,6)$. We have previously shown that Colombian PTC patients have a higher prevalence of indicators of severity and aggressive tumor behavior, such as large size, extra-thyroid extension, and lymph node and distant metastasis, than reported in developed countries (7). In contrast to overdiagnosis driven increases in incidence, which is common in developed countries, a smaller fraction of incidental diagnoses occurs in Colombia. This represents a unique opportunity to investigate the role of molecular makers in PTC etiology and prognosis.

Given the significant worldwide increase in PTC incidence (8), there is a great need to identify prognosis biomarkers that allow for effective patient stratification and management. The BRAF V600E mutation has been associated with tumorigenesis in a wide range of human malignancies (9) and represents the most common PTC mutation. BRAF V600E has been associated with clinicopathological features, such as lymph node metastasis and advanced disease stage $(1,10,11)$, although the evidence is not consistent $(12,13,14)$. Hence, $B R A F$ V600E on its own has limited utility as a prognosis PTC biomarker. More recently, two TERT promoter mutations, C228T and C250T, were found in $\sim 10 \%$ of PTC patients $(15,16,17,18,19,20)$ and have been associated with a higher risk of developing the classical variant of PTC (CVPTC) (15) and with disease severity $(15,18,19,20,21$, $22,23,24,25)$.

Given the high prevalence of BRAF and TERT mutations in PTC and their prognostic associations, there have been several studies showing the coexistence and cooperative role of these mutations in aggressive disease $(15,16,17,18,19,21,23,24,26,27)$, likely because the acquisition of a TERT mutation could extend the lifespan of $B R A F$ - or $R A S$-driven clones and enable accumulation of additional genetic defects leading to more advanced disease. Double mutants (i.e., carrying both TERT promoter and $B R A F$ mutations) are associated with older age at diagnosis, CVPTC $(18,19)$, large tumors $(18,22)$, extrathyroid extension $(18,22)$, lymph node $(18)$ and distant metastasis $(18,19)$, advanced $(18,19,22,26)$, recurrence (18), and mortality $(18,23)$. Given the importance of $B R A F$ and TERT mutations in PTC and the fact that these changes have not been examined in patients of Latino ancestry, we investigated the role of these mutations in clinical manifestations and the survival of patients recruited in a multi-center study in Colombia.

\section{Materials and methods}

\section{Study population}

The research protocol used in the study adhered to the Declaration of Helsinki and was approved by the Ethics Committees from University of Tolima (Ibague), Hospital Federico Lleras Acosta (Ibague), Clínica Tolima (Ibague), Hospital Hernando Moncaleano (Neiva), and Hospital Pablo Tobón Uribe (Medellin). These institutions are among the largest cancer hospitals in their corresponding cities. A total of 149 incident and histologically verified PTC patients, 81 with classical variant PTC (CVPTC) and 68 with follicular variant PTC (FVPTC), were recruited in between 2006 and 2016. All patients provided written informed consent, were interviewed in person by trained research nurses, and authorized access to pathology reports, clinical records, and to retrieve archival tumor samples for molecular analyses. We collected information on age of onset, gender, tumor size, focality, laterality, capsular or vascular invasion, lymph node metastases, extra-thyroid extension, distant metastasis, stage (AJCC), vital status, and cause of death.

\section{Mutation status}

A pathologist (MEB) demarcated tumor regions with $>80 \%$ tumor cells on hematoxylin and eosin (H\&E)stained slides. We isolated the DNA from the demarcated regions using Qiagen DNeasy Blood \& Tissue Kit and protocol. BRAF exon 15 and the TERT promoter region were amplified using previously reported primers (21, 28) and Sanger sequenced. The PCR amplification failed in three samples for $B R A F$ and eight for TERT (including those three samples that failed for $B R A F$ ) and were excluded from all subsequent analyses. The mutation status in BRAF (V600E) and TERT promoter (C228T, C250T) was inspected in electropherograms with 4 Peaks v. 1.7 (Nucleobytes B.V. 2004-2015) by two experienced independent researchers (APE and GPE). Mutation calling concordance was $100 \%$.

\section{Statistical analyses}

Statistical analysis was performed with R (https:// www.r-project.org/). We stratified clinicopathological variables by histology (CVPTC and FVPTC) and

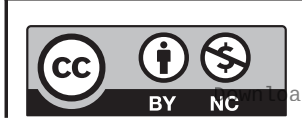

This work is licensed under a Creative Commons Attribution-NonCommercial 4.0 International License. ded from Bioscientifica.com at 04/26/2023 08:25:12AM via free access 
compared the histological subtypes using chi-square (for dichotomous variables) and Student's $t$ tests (for continuous variables, for which we verified that they were normally distributed). The association between mutation status and various characteristics, such as gender, age at diagnosis, histopathological subtype, tumor size, lymph node metastasis, and tumor stage, were determined by calculation of odds ratios; statistical significance was considered when two-sided $P$ values were $<0.05$. Comparisons of mutation prevalence were carried out using a Student's t test and data from the Cancer Genome Atlas (TCGA) (29) and the Johns Hopkins Hospital PTC cohort (23). Survival curves, stratified by mutational status, were calculated with the Kaplan-Meier method and compared with logrank test using survival v2.41-3 (https://cran.r-project. org/package=survival). Vital status (alive or death) was determined by investigating databases affiliated to the Colombian health system (Base de Datos Unica de Afiliados del Sistema General de Seguridad Social en Salud) and the National Civil Registry (Registraduria Nacional del Estado Civil) dataset. The last vital status assessment in all patients was carried out in December 2017 , which resulted in a mean follow-up time of 74.5 months/patient (standard deviation (s.D.): 29.8).

\section{Results}

\section{Characteristics of the study population}

The characteristics of Colombian patients are shown in Table 1. In total, 80\% (113 of 141) of these patients were women. The mean age of diagnosis was 45.9 years (s.D. $=13.7)$, large tumors $(>2 \mathrm{~cm})$ were diagnosed in $40 \%$ of the patients, $38 \%$ had multifocal disease, $20 \%$ had bilateral tumors, 30\% had capsular invasion, 38\% had vascular invasion, $36 \%$ had lymph node metastases, $26 \%$ had extra-thyroid extension, $6 \%$ had distant metastasis, and $30 \%$ of patients were classified with stage III/IV. At the final follow up, $94 \%$ of patients were alive. No statistical differences were found in tumor features between the two histopathological subtypes (Table 1).

Comparisons of clinical data in Colombian (Latino) patients with that in non-Latinos from TCGA and from the Johns Hopkins Hospital cohort are shown in Supplementary Table 1 (see section on supplementary data given at the end of this article). Relative to TCGA, we found a higher prevalence of FVPTC (47 vs 15\%, $P=1.74 \times 10^{-9}$ ) in Colombia. Comparisons with the Johns Hopkins Hospital cohort (23) revealed that Colombians had a higher prevalence of FVPTC (47 vs $25 \%, P=2.4 \times 10^{-8}$ ), large tumors (mean tumor size

Table 1 Clinical and histological characteristics of the 141 Colombian PTC patients analyzed in the study, stratified by histologic subtype.

\begin{tabular}{|c|c|c|c|c|}
\hline \multirow[b]{2}{*}{ Clinical feature } & \multicolumn{3}{|c|}{ Number of patients (\%) } & \multirow[b]{2}{*}{$P$ value } \\
\hline & All $(n=141)$ & CVPTC $(n=75)$ & FVPTC $(n=66)$ & \\
\hline Male gender & 28 (19.9) & 18 & 10 & 0.189 \\
\hline Mean age in years & 45.9 & 45.1 & 46.7 & 0.506 \\
\hline$<45$ years & $57(40.4)$ & 33 & 24 & \\
\hline$\geq 45$ years & $84(59.6)$ & 42 & 42 & 0.357 \\
\hline Mean tumor size & 2.35 & 2.37 & 2.32 & 0.858 \\
\hline Large tumors, $>2 \mathrm{~cm}$ & $54(40.3)$ & 26 & 28 & 0.436 \\
\hline Multifocal tumors & $51(37.5)$ & 24 & 27 & 0.352 \\
\hline Bilateral tumors & $25(19.7)$ & 14 & 11 & 0.653 \\
\hline Capsular invasion & $38(30.2)$ & 24 & 14 & 0.052 \\
\hline Vascular invasion & $47(38.2)$ & 24 & 23 & 0.978 \\
\hline LNM & $46(36.2)$ & 29 & 17 & 0.080 \\
\hline ETT & $34(26.2)$ & 19 & 15 & 0.555 \\
\hline Distant metastasis & $8(5.7)$ & 6 & 2 & 0.203 \\
\hline Stage III-IV ${ }^{a}$ & $42(30.4)$ & 25 & 17 & 0.302 \\
\hline \multicolumn{5}{|l|}{ Vital status ${ }^{b}$} \\
\hline Alive & $129(94.2)$ & 66 & 63 & \\
\hline Dead & $8(5.8)$ & 5 & 3 & 0.719 \\
\hline Cancer-related death & $4(2.9)$ & 3 & 1 & 0.620 \\
\hline Mean follow-up in months & 74.5 & 73.5 & 75.6 & 0.669 \\
\hline
\end{tabular}

aBased on American Joint Committee on Cancer (AJCC) protocol of classification but including two patients diagnosed before 45 years with metastasis. bVital status was unknown in four patients.

CVPTC, classical variant of PTC (papillary thyroid carcinoma); FVPTC, follicular variant of PTC; LNM, lymph node metastasis; ETT, extra-thyroid extension.

https://ec.bioscientifica.com

https://doi.org/10.1530/EC-19-0376 (c) 2019 The authors Published by Bioscientifica Ltd

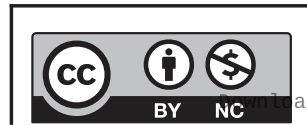

This work is licensed under a Creative Commons Attribution-NonCommercial 4.0 International License. ded from Bioscientifica.com at 04/26/2023 08:25:12AM via free access 
$2.35 \mathrm{~cm}$ vs $1.5 \mathrm{~cm}, P=5.8 \times 10^{-51}$ ), vascular invasion ( $38 \mathrm{vs}$ $\left.15 \%, P=1.5 \times 10^{-10}\right)$, extra-thyroid extension ( 26 vs $18 \%$, $P=0.016$ ), and advanced stage ( 30 vs $20 \%, P=0.004$ ). These comparisons with US patients suggest that PTC diagnoses in Colombia are belated, resulting in a higher prevalence of advanced tumors.

\section{Individual effects of BRAF and TERT mutations}

The prevalence of BRAF V600E mutations in our study was $60 \%$ (49 of 75 CVPTCs, and 35 of 66 FVPTCs had V600E), which was lower than in TCGA data (70\%, $P=0.058$, Supplementary Table 1) but higher than in the Johns Hopkins Hospital cohort $\left(34 \%, P=2.0 \times 10^{-5}\right.$, Supplementary Table 1). We found that BRAF V600E was more frequent in patients with lymph node metastases (34 of 84 vs 12 of $57 ; P=0.04$, Supplementary Table 2 ). As reported in other populations, CVPTC patients with advanced stage tumors had a higher prevalence of $B R A F$ mutation ( 21 of 25 vs 28 of 48 of early stage CVPTCs; $P=0.03$ not shown) $(1,10,11)$.

The presence of high-risk clinicopathological characteristics did not show sex differences although most of aggressive features had a higher frequency in men (Supplementary Table 3). This was also observed when patients were stratified by BRAF mutation status, where men had a higher risk of prevalence of BRAF wild type tumors with lymph node metastasis (5 of 12 men and 7 of 45 women who were $B R A F$ wild type had lymph node metastases, $P=0.03$ ). The latter finding is consistent with previous reports suggesting that male sex is a risk factor for aggressive disease $(30,31)$.

The two mutations in the TERT promoter were mutually exclusive in our study and were identified in $16 \%$ of the patients (14 patients had tumors with the TERT C228T mutation and nine with TERT C250T). This TERT mutation prevalence in Colombia was two-fold higher than in TCGA ( $8 \%, P=0.017$; Supplementary Table 1) $(23,29)$. Consistent with previous reports (21), we found that TERT mutations were associated with a late age of diagnosis (mean age at diagnosis 51.3 years for TERT mutant tumors vs 44.8 years for TERT wild type tumors, $P=0.04)$. TERT mutations were also more frequent in patients with extra-thyroid extension (9 of 23 vs 25 of $118, P=0.007)$, and with advanced stage tumors (13 of 25 vs 29 of $118, P=0.001$ ) (Supplementary Table 2). These associations between TERT mutation status and aggressive clinical manifestations are consistent with previous reports in other populations $(15,18,22,23,24)$.
The combined effects of BRAF V600E and TERT promoter mutations

We found that $10 \%(n=14)$ of our patients had mutations in both BRAF and TERT (herein referred to as doublemutants), a prevalence that is higher than in the Johns Hopkins Hospital cohort (6\%, $P=0.001$, Supplementary Table 1). The comparisons between the clinicopathological characteristics of double-mutants with those in wild type patients for both genes (double-wild types, $n=48$ patients) are shown in Table 2. Comparisons between all four mutation subgroups are shown in Supplementary Table 4. Compared to double-wild types, double-mutants were diagnosed at older age ( 56 years vs 45 years, $P=0.003$ ) and had a higher prevalence of CVPTC (11 of 14 vs 21 of 48 , $P=0.022$ ), large tumors ( 8 of 14 vs 16 of $48, P=0.026$ ), lymph node metastasis (7 of 14 vs 9 of $48, P=0.009$ ), extra-thyroid extension ( 6 of 14 vs 11 of $48, P=0.028$ ), and tumors with advanced stage (11 of 14 vs 10 of 48 , $\left.P=6.0 \times 10^{-5}\right)$. Therefore, our study in Latinos replicates previously reported associations of double mutants in white/Caucasian patients with CVPTC $(18,19)$, age of diagnosis $(18,19,22)$, tumor size $(18,22)$, extra-thyroid extension $(18,22)$, lymph node metastasis (18), and advanced disease stage $(18,19,22,26)$.

\section{Exploratory analyses of survival}

In our study, the overall mortality (i.e., by any cause) was 6\% (8 of 137 patients in available vital status; Table 1). Of the eight deceased patients, four died of cancer and four of unknown reasons. Cancer-specific mortality was associated with older age at diagnosis $(\mathrm{HR}=1.20 ; P=0.017)$ and patients with TERT promoter mutations generally had a lower chance of survival (HR=3.9; $P=0.17$ and Fig. 1 ). This association with mortality in our study replicates the prognostic value of TERT mutations in an independent population $(21,22,24,25)$. Given the relatively small sample size of our study, we were unable to determine the statistical support of potential prognostic factors, such as BRAF mutations, TERT mutations, older age, advance stage, and CVPTC histology, to survival. Future studies should include a larger sample size to further investigate factors related to survival.

\section{Discussion}

The increment of PTC incidence in developed countries might be explained by the over-diagnosis of small

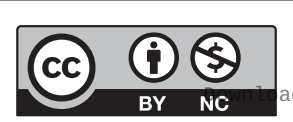

This work is licensed under a Creative Commons Attribution-NonCommercial 4.0 International License. ded from Bioscientifica.com at 04/26/2023 08:25:12AM via free access 
Table 2 Comparison of clinical characteristics between wild-type tumors versus those with both BRAF V600E and TERT promoter mutations (double mutants).

\begin{tabular}{|c|c|c|c|c|}
\hline \multirow[b]{2}{*}{ Clinical feature } & \multicolumn{2}{|c|}{ Number of patients (\%) } & \multirow[b]{2}{*}{ OR $(95 \% \mathrm{Cl})$} & \multirow[b]{2}{*}{ P value ${ }^{a}$} \\
\hline & No mutation $(n=48)$ & Double mutants $(n=14)$ & & \\
\hline Male gender & 10 & 4 & $1.52(0.39-5.88)$ & 0.542 \\
\hline Mean age (S.D.) & $44.7(14.6)$ & $55.5(9.33)$ & NA & 0.003 \\
\hline$<45$ years & 20 & 3 & & \\
\hline$\geq 45$ years & 28 & 11 & $2.62(0.65-10.62)$ & 0.168 \\
\hline CVPTC subtype & 21 & 11 & 4.71 (1.16-19.08) & 0.022 \\
\hline Large tumors ( $>2 \mathrm{~cm})$ & 16 & 8 & $4.83(1.12-20.82)$ & 0.026 \\
\hline Multifocal tumors & 17 & 4 & $0.97(0.25-3.82)$ & 0.971 \\
\hline Bilateral tumors & 5 & 2 & $1.56(0.26-9.37)$ & 0.628 \\
\hline Capsular invasion & 12 & 5 & $3.33(0.76-14.54)$ & 0.098 \\
\hline Vascular invasion & 16 & 5 & $2.92(0.61-13.85)$ & 0.166 \\
\hline LNM & 9 & 7 & $6.03(1.43-25.32)$ & 0.009 \\
\hline ETT & 11 & 6 & $4.64(1.10-19.50)$ & 0.028 \\
\hline Distant metastasis & 3 & 2 & $2.50(0.37-16.70)$ & 0.331 \\
\hline Stage III-IVb & 10 & 11 & 19.80 (3.76-104.3) & $6.0 \times 10^{-5}$ \\
\hline \multicolumn{5}{|l|}{ Vital status } \\
\hline Alive & 43 & 13 & Reference & \\
\hline Dead & 4 & 1 & $0.83(0.08-8.06)$ & 0.870 \\
\hline Cancer-related death & 1 & 1 & 3.31 (0.19-56.64) & 0.428 \\
\hline
\end{tabular}

aStatistically significant two-tailed $P$ values are shown in bold. ${ }^{b}$ Based on American Joint Committee on Cancer (AJCC) protocol of classification but including two patients diagnosed before 45 years with metastasis.

CVPTC, classical variant of PTC (papillary thyroid carcinoma); ETT, extra-thyroid extension; FVPTC, follicular variant of PTC; LNM: lymph node metastasis; S.D., standard deviation.

incidental tumors (32). However, few studies have also noted that the prevalence of large $(33,34)$ and aggressive tumors is also increasing $(33,35)$, suggesting that factors other than overdiagnosis might be affecting the increase of PTC incidence (36). Relative to reports in white patients from the U.S. (23), we found a higher prevalence of aggressive disease. A total of 30\% of Colombian patients had stage III/IV tumors, $40 \%$ had large tumors $>2 \mathrm{~cm}$, and $6 \%$ had metastases to lungs and medulla, which support the notion of belated diagnosis rather than of incidental over-diagnosis. Therefore, the absence of confounding factors resulting from over-diagnosis indicates that factors influencing incidence and disease aggressiveness can be better studied in populations like Colombia.

Thyroid cancer is now the third most diagnosed cancer in Colombian women (6) and the second in US Latinas. A recent report from the American Cancer Society found that $9 \%$ of the newly diagnosed cancer patients in US Latinas $(2,6)$ and $5 \%$ in US white women are now PTC patients (6). The high incidence of PTC in Latinas is puzzling and could be explained, in part, by high rates of obesity in both US Latinas (where overweight/obesity rates are $\sim$ two-fold higher than in white women) (37) and Colombians (where obesity rates increased by $18 \%$ between 2005 and 2010) $(38,39,40)$. Other populationspecific factors, such as American Indian ancestry, which influences cancer patters in the region $(41,42,43)$ or other unidentified etiological factors may mediate the risk of PTC in the population.

Even though recent studies suggest that CVPTCs tend to have more aggressive clinical manifestations

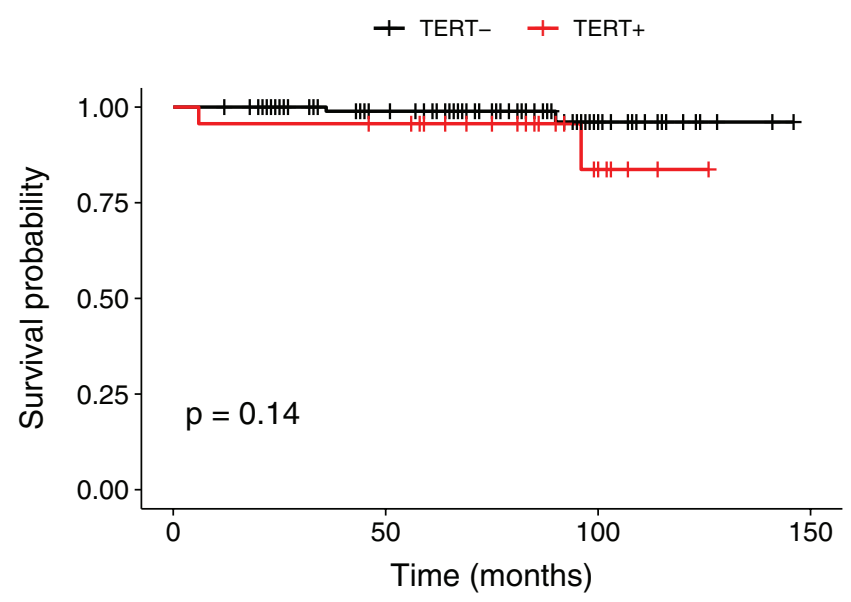

Number at risk

$\begin{array}{ccccc}\text { TERT- } & 110 & 86 & 19 & 0 \\ \text { TERT }+ & 23 & 21 & 6 & 0\end{array}$

Figure 1

Effects of TERT promoter mutations on cancer-survival of PTC patients (log-rank test $=2.16, \mathrm{df}=1, P=0.14)$. 
and worse outcomes (44), our study failed to detect statistically significant differences between the CVPTC and FVPTC subtypes (Table 1). However, we found a trend where CVPTCs, relative to FVPTCs, had a higher frequency of high-risk features, such as vascular invasion (32 vs $21 \%, P=0.052$, Table 1 ) or lymph node metastasis (39 vs $23 \%, P=0.08$, Table 1 ), which is consistent with a previous report in 1293 patients (44). Consistent with this observation, we found that most double mutants (11 out 14, Table 2) were CVPTCs, which may indicate that this histological subtype could be more aggressive than FVPTCs. We acknowledge that out failure to detect differences in clinical manifestations between the two histological subtypes is likely the result of limited power given our small sample size.

We found TERT mutations in 16\% of the patients and these mutations were associated with a two-fold increment of the risk of extra-thyroid extension and of advanced stage. When BRAF and TERT promoter mutations were analyzed together, double-mutants compared to doublewild types had a six-fold higher risk of lymph node metastasis and a 20-fold higher risk of advanced tumors. The coexistence of TERT and BRAF mutations was also significantly associated with older age (Table 2). These clinical features have been associated with mortality in several studies $(16,22,24,25,26,45)$, demonstrating that TERT mutations, rather than $B R A F-V 600 E$, were restricted to PTC patients $>45$ years. This highlights the specific role of the age of patients in the mutational event (21). Hence, our study provides further support for the prognostic importance of TERT mutations in PTC.

PTC survival is mainly affected by tumor stage, with patients with stage IV tumors having the lowest survival rates (46). Survival up to 10 years in our sample was $89 \%$, which is similar to the survival rate found by a recent report from the Colombian National Cancer Institute (47) but lower than reports from US patients (i.e., 95\%) (48). This observation further suggests that relative to US white patients, Colombians are more likely to have severe PTC. Future studies involving US Latinos and other US minorities are therefore warranted to assess whether survival and clinical manifestations are more severe, relative to white patients.

In the Johns Hopkins Hospital cohort, the analyses of the combined effects of BRAF-TERT mutations (i.e., doublemutants) revealed a significant association with mortality, which remained strong after multivariate adjustment for all of the conventional clinicopathological characteristics, demonstrating the independent role of double-mutant stats in PTC-related mortality. Exploratory analyses in our cohort suggested that TERT promoter mutations and a late age of onset appear to be stronger predictors than $B R A F$ mutations. We acknowledge that our sample size is small and hence, under-powered to draw stronger conclusions on the combined role of BRAF/TERT mutation status on PTC mortality. Additionally, the clinic-based setting of our study may not reflect the characteristics of the patients of the general population and may have introduced some biases. However, population-based studies in Colombia (and in most of Latin America) are unfeasible due to the lack of country-wide cancer registries. Here, we made an effort to recruit patients from the largest cancer hospitals in their corresponding cities. Nonetheless, we believe that the multi-site nature of the study is a close reflection of the characteristics of the general population.

In summary, we found a high fraction of Colombian patients with large and advanced tumors and with distant metastasis, suggesting that most patients were not the result of incidental findings. To our knowledge, this is the first study of $B R A F$ and TERT promoter mutations in Colombia and in Latinos. We found strong associations between BRAF and TERT promoter mutations and PTC prognosis, suggesting that these mutations could be a factor explaining the aggressiveness of the disease in this study. We believe that this report represents an important initial step to develop precision medicine for PTC in Latinos from the Americas.

\section{Supplementary data}

This is linked to the online version of the paper at https://doi.org/10.1530/ EC-19-0376.

\section{Declaration of interest}

The authors declare that there is no conflict of interest that could be perceived as prejudicing the impartiality of the research reported.

\section{Funding}

This study was supported by grants from COLCIENCIAS (Graduate Studentship from Programa de Doctorados Nacionales to APE-F, COLCIENCIAS - 647/2014), L'OREAL-UNESCO-ICETEX-COLCIENCIAS (Programa Mujeres para la Ciencia to APE-F - 3900917/2017), and Universidad del Tolima (Grants to MEB and ME, projects 400111, 360113, and 170130517). L G C-C acknowledges funding from the University of California Davis (start-up funds and Dean's Fellowship in Precision Health Equity) and from the National Cancer Institute of the National Institutes of Health (P30CA093373 Cancer Center Support Grant). This content is solely the responsibility of the authors and does not necessarily represent the official views of the National Institutes of Health.
This work is licensed under a Creative Commons Attribution-NonCommercial 4.0 International License. ded from Bioscientifica.com at 04/26/2023 08:25:12AM via free access 


\section{Acknowledgments}

The authors are grateful to all of the individuals who participated in the study and to the organizations that provided research funding.

\section{References}

1 Xing M, Alzahrani AS, Carson KA, Viola D, Elisei R, Bendlova B, Yip L, Mian C, Vianello F, Tuttle RM, et al. Association between BRAF V600E mutation and mortality in patients with papillary thyroid cancer. JAMA 2013309 1493-1501. (https://doi.org/10.1001/ jama.2013.3190)

2 Miller KD, Goding Sauer A, Ortiz AP, Fedewa SA, Pinheiro PS, Tortolero-Luna G, Martinez-Tyson D, Jemal A \& Siegel RL. Cancer statistics for Hispanics/Latinos, 2018. CA: A Cancer Journal for Clinicians 201868 425-445. (https://doi.org/10.3322/caac.21494)

3 Siegel RL, Fedewa SA, Miller KD, Goding-Sauer A, Pinheiro PS, Martinez-Tyson D \& Jemal A. Cancer statistics for Hispanics/Latinos, 2015. CA: A Cancer Journal for Clinicians 201565 457-480. (https:// doi.org/10.3322/caac.21314)

4 Carvajal-Carmona LG, Ophoff R, Service S, Hartiala J, Molina J, Leon P, Ospina J, Bedoya G, Freimer N \& Ruiz-Linares A. Genetic demography of Antioquia (Colombia) and the Central Valley of Costa Rica. Human Genetics 2003112 534-541. (https://doi. org/10.1007/s00439-002-0899-8)

5 Criollo-Rayo AA, Bohorquez M, Prieto R, Howarth K, Culma C, Carracedo A, Tomlinson I, Echeverry de Polnaco MM, Carvajal Carmona LG \& CHIBCHA Consortium. Native American gene continuity to the modern admixed population from the Colombian Andes: implication for biomedical, population and forensic studies. Forensic Science International: Genetics 201836 e1-e7. (https://doi. org/10.1016/j.fsigen.2018.06.006)

6 International Agency for Research on Cancer. CANCER Today, Data Visualization Tools for Exploring the Global Cancer Burden in 2018. Lyon, France: IARC, 2018. (available at: https://gco.iarc.fr/today/home)

7 Estrada-Florez AP, Bohorquez ME, Sahasrabudhe R, Prieto R, Lott P, Duque CS, Donado J, Mateus G, Bolanos F, Velez A, et al. Clinical features of Hispanic thyroid cancer cases and the role of known genetic variants on disease risk. Medicine 201695 e4148. (https://doi. org/10.1097/MD.0000000000004148)

8 Wiltshire JJ, Drake TM, Uttley L \& Balasubramanian SP. Systematic review of trends in the incidence rates of thyroid cancer. Thyroid 201626 1541-1552. (https://doi.org/10.1089/thy.2016.0100)

9 Davies H, Bignell GR, Cox C, Stephens P, Edkins S, Clegg S, Teague J, Woffendin H, Garnett MJ, Bottomley W, et al. Mutations of the BRAF gene in human cancer. Nature 2002417 949-954. (https://doi. org/10.1038/nature00766)

10 Elisei R, Viola D, Torregrossa L, Giannini R, Romei C, Ugolini C, Molinaro E, Agate L, Biagini A, Lupi C, et al. The BRAF(V600E) mutation is an independent, poor prognostic factor for the outcome of patients with low-risk intrathyroid papillary thyroid carcinoma: single-institution results from a large cohort study. Journal of Clinical Endocrinology and Metabolism 201297 4390-4398. (https://doi. org/10.1210/jc.2012-1775)

11 Fakhruddin N, Jabbour M, Novy M, Tamim H, Bahmad H, Farhat F, Zaatari G, Aridi T, Kriegshauser G, Oberkanins C, et al. BRAF and NRAS mutations in papillary thyroid carcinoma and concordance in BRAF mutations between primary and corresponding lymph node metastases. Scientific Reports 20177 4666. (https://doi.org/10.1038/ s41598-017-04948-3)

12 Gandolfi G, Sancisi V, Piana S \& Ciarrocchi A. Time to re-consider the meaning of BRAF V600E mutation in papillary thyroid carcinoma. International Journal of Cancer 2015137 1001-1011. (https://doi. org/10.1002/ijc.28976)
13 Dong SY, Zeng RC, Jin LP, Yang F, Zhang XJ, Yao ZH, Zhang XH \& Wang OC. BRAF(V600E) mutation is not associated with central lymph node metastasis in all patients with papillary thyroid cancer: different histological subtypes and preoperative lymph node status should be taken into account. Oncology Letters 201714 4122-4134.

14 Gouveia C, Can NT, Bostrom A, Grenert JP, van Zante A \& Orloff LA. Lack of association of BRAF mutation with negative prognostic indicators in papillary thyroid carcinoma: the University of California, San Francisco, experience. JAMA Otolaryngology: Head and Neck Surgery 2013139 1164-1170. (https://doi.org/10.1001/ jamaoto.2013.4501)

15 Vinagre J, Almeida A, Populo H, Batista R, Lyra J, Pinto V, Coelho R, Celestino R, Prazeres H, Lima L, et al. Frequency of TERT promoter mutations in human cancers. Nature Communications 201342185. (https://doi.org/10.1038/ncomms3185)

16 Liu X, Bishop J, Shan Y, Pai S, Liu D, Murugan AK, Sun H, El-Naggar AK \& Xing M. Highly prevalent TERT promoter mutations in aggressive thyroid cancers. Endocrine-Related Cancer 201320 603-610. (https://doi.org/10.1530/ERC-13-0210)

17 Landa I, Ganly I, Chan TA, Mitsutake N, Matsuse M, Ibrahimpasic T, Ghossein RA \& Fagin JA. Frequent somatic TERT promoter mutations in thyroid cancer: higher prevalence in advanced forms of the disease. Journal of Clinical Endocrinology and Metabolism 201398 E1562-E1566. (https://doi.org/10.1210/jc.2013-2383)

18 Xing M, Liu R, Liu X, Murugan AK, Zhu G, Zeiger MA, Pai S \& Bishop J. BRAF V600E and TERT promoter mutations cooperatively identify the most aggressive papillary thyroid cancer with highest recurrence. Journal of Clinical Oncology 201432 2718-2726. (https:// doi.org/10.1200/JCO.2014.55.5094)

19 Gandolfi G, Ragazzi M, Frasoldati A, Piana S, Ciarrocchi A \& Sancisi V. TERT promoter mutations are associated with distant metastases in papillary thyroid carcinoma. European Journal of Endocrinology 2015172 403-413. (https://doi.org/10.1530/EJE-140837)

20 Muzza M, Colombo C, Rossi S, Tosi D, Cirello V, Perrino M, De Leo S, Magnani E, Pignatti E, Vigo B, et al. Telomerase in differentiated thyroid cancer: promoter mutations, expression and localization. Molecular and Cellular Endocrinology 2015399 288-295. (https://doi. org/10.1016/j.mce.2014.10.019)

21 Liu T, Wang N, Cao J, Sofiadis A, Dinets A, Zedenius J, Larsson C $\&$ Xu D. The age- and shorter telomere-dependent TERT promoter mutation in follicular thyroid cell-derived carcinomas. Oncogene 2014 33 4978-4984. (https://doi.org/10.1038/onc.2013.446)

22 Liu X, Qu S, Liu R, Sheng C, Shi X, Zhu G, Murugan AK, Guan H, $\mathrm{Yu} \mathrm{H}$, Wang Y, et al. TERT promoter mutations and their association with BRAF V600E mutation and aggressive clinicopathological characteristics of thyroid cancer. Journal of Clinical Endocrinology and Metabolism 201499 E1130-E1136. (https://doi.org/10.1210/jc.20134048)

23 Liu R, Bishop J, Zhu G, Zhang T, Ladenson PW \& Xing M. Mortality risk stratification by combining BRAF V600E and TERT promoter mutations in papillary thyroid cancer: genetic duet of BRAF and TERT promoter mutations in thyroid cancer mortality. JAMA Oncology 20173 202-208. (https://doi.org/10.1001/ jamaoncol.2016.3288)

24 Melo M, da Rocha AG, Vinagre J, Batista R, Peixoto J, Tavares C, Celestino R, Almeida A, Salgado C, Eloy C, et al. TERT promoter mutations are a major indicator of poor outcome in differentiated thyroid carcinomas. Journal of Clinical Endocrinology and Metabolism 201499 E754-E765. (https://doi.org/10.1210/jc.2013-3734)

25 Bullock M, Ren Y, O’Neill C, Gill A, Aniss A, Sywak M, Sidhu S, Delbridge L, Learoyd D, de Vathaire F, et al. TERT promoter mutations are a major indicator of recurrence and death due to papillary thyroid carcinomas. Clinical Endocrinology 201685 283-290. (https://doi.org/10.1111/cen.12999) https://ec.bioscientifica.com https://doi.org/10.1530/EC-19-0376 (c) 2019 The authors Published by Bioscientifica Ltd

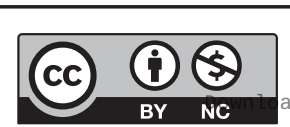

This work is licensed under a Creative Commons Attribution-NonCommercial 4.0 International License. ded from Bioscientifica.com at 04/26/2023 08:25:12AM 
26 Lee SE, Hwang TS, Choi YL, Han HS, Kim WS, Jang MH, Kim SK \& Yang JH. Prognostic significance of TERT promoter mutations in papillary thyroid carcinomas in a BRAF(V600E) mutation-prevalent population. Thyroid 201626 901-910. (https://doi.org/10.1089/ thy.2015.0488)

27 Insilla AC, Proietti A, Borrelli N, Macerola E, Niccoli C, Vitti P, Miccoli P \& Basolo F. TERT promoter mutations and their correlation with BRAF and RAS mutations in a consecutive cohort of 145 thyroid cancer cases. Oncology Letters 201815 2763-2770. (https://doi. org/10.3892/ol.2017.7675)

$28 \mathrm{Xu}$ X, Quiros RM, Gattuso P, Ain KB \& Prinz RA. High prevalence of BRAF gene mutation in papillary thyroid carcinomas and thyroid tumor cell lines. Cancer Research 200363 4561-4567.

29 Cancer Genome Atlas Research Network. Integrated genomic characterization of papillary thyroid carcinoma. Cell 2014159 676-690. (https://doi.org/10.1016/j.cell.2014.09.050)

30 Suman P, Wang CH, Abadin SS, Moo-Young TA, Prinz RA \& Winchester DJ. Risk factors for central lymph node metastasis in papillary thyroid carcinoma: a National Cancer Data Base (NCDB) study. Surgery 2016159 31-39. (https://doi.org/10.1016/j. surg.2015.08.032)

31 Wang F, Zhao S, Shen X, Zhu G, Liu R, Viola D, Elisei R, Puxeddu E, Fugazzola L, Colombo C, et al. BRAF V600E confers male sex disease-specific mortality risk in patients with papillary thyroid cancer. Journal of Clinical Oncology 201836 2787-2795. (https://doi. org/10.1200/JCO.2018.78.5097)

32 Jegerlehner S, Bulliard JL, Aujesky D, Rodondi N, Germann S, Konzelmann I, Chiolero A \& NICER Working Group. Overdiagnosis and overtreatment of thyroid cancer: a population-based temporal trend study. PLOS ONE 201712 e0179387. (https://doi.org/10.1371/ journal.pone.0179387)

33 Enewold L, Zhu K, Ron E, Marrogi AJ, Stojadinovic A, Peoples GE $\&$ Devesa SS. Rising thyroid cancer incidence in the United States by demographic and tumor characteristics, 1980-2005. Cancer Epidemiology, Biomarkers and Prevention 200918 784-791. (https:// doi.org/10.1158/1055-9965.EPI-08-0960)

34 Pellegriti G, Frasca F, Regalbuto C, Squatrito S \& Vigneri R. Worldwide increasing incidence of thyroid cancer: update on epidemiology and risk factors. Journal of Cancer Epidemiology 2013 2013 965212. (https://doi.org/10.1155/2013/965212)

35 Simard EP, Ward EM, Siegel R \& Jemal A. Cancers with increasing incidence trends in the United States: 1999 through 2008. CA: A Cancer Journal for Clinicians 201262 118-128. (https://doi. org/10.3322/caac.20141)

36 McLeod DS, Sawka AM \& Cooper DS. Controversies in primary treatment of low-risk papillary thyroid cancer. Lancet $2013 \mathbf{3 8 1}$ 1046-1057. (https://doi.org/10.1016/S0140-6736(12)62205-3)

37 Hales C, Carroll M, Fryar C \& Ogden C. Prevalence of obesity among adults and youth: United States, 2015-2016. In NCHS Data Brief, No. 288, October 2017. Hyattsville, MD, USA: U.S. Department of HHS,
CDC, NCHS, 2017. (available at: https://www.cdc.gov/nchs/data/ databriefs/db288.pdf)

38 Forrest KYZ, Leeds MJ \& Ufelle AC. Epidemiology of obesity in the Hispanic adult population in the United States. Family and Community Health 201740 291-297. (https://doi.org/10.1097/ FCH.0000000000000160)

39 Harikrishna A, Ishak A, Ellinides A, Saad R, Christodoulou H, Spartalis E \& Paschou SA. The impact of obesity and insulin resistance on thyroid cancer: a systematic review. Maturitas 2019125 45-49. (https://doi.org/10.1016/j.maturitas.2019.03.022)

40 Kasper NM, Herran OF \& Villamor E. Obesity prevalence in Colombian adults is increasing fastest in lower socio-economic status groups and urban residents: results from two nationally representative surveys. Public Health Nutrition 201417 2398-2406. (https://doi.org/10.1017/S1368980013003418)

41 Hoffman J, Fejerman L, Hu D, Huntsman S, Li M, John EM, TorresMejia G, Kushi L, Ding YC, Weitzel J, et al. Identification of novel common breast cancer risk variants at the $6 \mathrm{q} 25$ locus among Latinas. Breast Cancer Research 201921 3. (https://doi.org/10.1186/s13058018-1085-9)

42 Sahasrabudhe R, Estrada A, Lott P, Martin L, Echeverry GP, Velez A, Neta G, Takahasi M, Saenko V, Mitsutake N, et al. The 8q24 rs6983267G variant is associated with increased thyroid cancer risk. Endocrine-Related Cancer 201522 841-849. (https://doi.org/10.1530/ ERC-15-0081)

43 Fejerman L, Ahmadiyeh N, Hu D, Huntsman S, Beckman KB, Caswell JL, Tsung K, John EM, Torres-Mejia G, Carvajal-Carmona L, et al. Genome-wide association study of breast cancer in Latinas identifies novel protective variants on $6 \mathrm{q} 25$. Nature Communications 20145 5260. (https://doi.org/10.1038/ncomms6260)

44 Henke LE, Pfeifer JD, Baranski TJ, DeWees T \& Grigsby PW. Longterm outcomes of follicular variant vs classic papillary thyroid carcinoma. Endocrine Connections 20187 1226-1235. (https://doi. org/10.1530/EC-18-0264)

45 Nixon IJ, Wang LY, Palmer FL, Tuttle RM, Shaha AR, Shah JP, Patel SG \& Ganly I. The impact of nodal status on outcome in older patients with papillary thyroid cancer. Surgery 2014156 137-146. (https:// doi.org/10.1016/j.surg.2014.03.027)

46 Loh KC, Greenspan FS, Gee L, Miller TR \& Yeo PP. Pathological tumor-node-metastasis (pTNM) staging for papillary and follicular thyroid carcinomas: a retrospective analysis of 700 patients. Journal of Clinical Endocrinology and Metabolism 199782 3553-3562. (https:// doi.org/10.1210/jcem.82.11.4373)

47 Pardo C \& de Vries E. Supervivencia global de pacientes con cáncer en el Instituto Nacional de Cancerología (Inc). Revista Colombiana de Cancerología 201721 12-18. (https://doi.org/10.1016/j. rccan.2017.01.003)

48 Sipos JA \& Mazzaferri EL. Thyroid cancer epidemiology and prognostic variables. Clinical Oncology 201022 395-404. (https://doi. org/10.1016/j.clon.2010.05.004)

Received in final form 8 August 2019

Accepted 22 August 2019

Accepted Preprint published online 27 August 2019 https://ec.bioscientifica.com https://doi.org/10.1530/EC-19-0376 (c) 2019 The authors Published by Bioscientifica Ltd

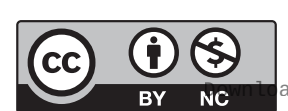

This work is licensed under a Creative Commons Attribution-NonCommercial 4.0 International License. ded from Bioscientifica.com at 04/26/2023 08:25:12AM 